\title{
Programa Nacional do Livro Didático de Física: subsídios para pesquisas
}

\author{
National Physics Textbook Program: research grants
}

\author{
Milton Schivani ${ }^{* 1,30}$, Gustavo Fontoura de Souza ${ }^{2}$, Natália Lira ${ }^{3}$ \\ ${ }^{1}$ Universidade Federal do Rio Grande do Norte, Departamento de Física, Campus Universitário, Lagoa Nova, Natal, RN, Brasil \\ ${ }^{2}$ Instituto Federal de Educação, Ciência e Tecnologia do Rio Grande do Norte, Parnamirim, RN, Brasil \\ ${ }^{3}$ Universidade Federal do Rio Grande do Norte, Centro de Ciências Exatas e da Terra, Programa de Pós-Graduação em Ensino \\ de Ciências Naturais e Matemática, Natal, RN, Brasil
}

Recebido em 06 de Janeiro de 2020. Aceito em 27 de Março de 2020.

\begin{abstract}
O livro didático de Física continua sendo um dos principais recursos utilizados na Educação Básica Pública Brasileira, sendo objeto de estudo de diversas pesquisas. Contudo, considerações sobre a abrangência nacional dos livros selecionados para análise não estão presentes em muitas dessas pesquisas, podendo dificultar ou impedir uma melhor interpretação dos resultados obtidos e definição dos critérios de escolha das obras para análise. Assim, objetivando fornecer subsídios para apoiar pesquisas sobre livro didático de Física do Ensino Médio, efetuamos um levantamento do total de coleções adotadas em todo o território brasileiro para o triênio 2018-2020. Os dados foram obtidos junto ao Fundo Nacional de Desenvolvimento da Educação (FNDE), correspondem às escolhas efetuadas pelas escolas públicas ao final do ano de 2017. Em linhas gerais, observou-se uma significativa uniformidade nacional, especialmente nas regiões sudeste e nordeste. Uma coleção, reconhecida como de perfil mais tradicional, destacou-se como sendo aquela com maior número de livros adotados em 21 (vinte e um) estados.
\end{abstract}

Palavras-chave: Livro Didático, Física, FNDE, PNLD.

The Physics textbook remains one of the main resources used in the Brazilian Public Basic Education, being subject of study of several researches. However, considerations about the national reach of the books selected for analysis are not present in many of these researches, which may hinder or prevent a better interpretation of the results achieved and definition of the criteria for choosing works for analysis. Thus, aiming to provide subsidies to support research on High School Physics textbook, we surveyed the total of collections adopted throughout the Brazilian territory for the 2018-2020 triennium. The data were obtained from the National Fund for the Development of Education (FNDE), corresponding to the choices made by public schools at the end of 2017 . In general, a significant national uniformity was observed, especially in the southeast and northeast areas. One collection, recognized as having a more traditional profile, stood out as the one with the largest number of books adopted in 21 (twenty-one) states.

Keywords: Textbook, Physics, FNDE, PNLD.

\section{Introdução}

O livro didático ocupa papel de destaque dentre os programas educacionais do Brasil, tanto em termos de investimento quanto em relação ao número de exemplares distribuídos, colocando o Programa Nacional do Livro Didático (PNLD) entre um dos maiores programas de livro didático do mundo [1-2].

O PNLD foi instituído oficialmente por meio do Decreto 91.542 de 19/08/19851 que trouxe princípios inéditos de aquisição e distribuição universal gratuita de livros didáticos para estudantes da então rede pública brasileira de ensino de $1^{\circ}$ grau e implicou em "um projeto

\footnotetext{
*Endereço de correspondência: schivani@fisica.ufrn.br ${ }^{1}$ Disponível em: <https://www2.camara.leg.br/legin/fed/ decret/1980-1987/decreto-91542-19-agosto-1985-441959publicacaooriginal-1-pe.html>. Acesso em: 25 ago. 2019.
}

de nação a ser empreendido na redemocratização do país, visto que políticas educacionais sempre se circunscrevem em contextos de políticas mais gerais." ([2], p.20).

Contando com mais de 30 anos, o PNLD2 ${ }^{2}$ abrange hoje toda a Educação Básica Pública Brasileira com distribuição de obras didáticas de praticamente todos os componentes curriculares aos estudantes e professores. De acordo com dados estatísticos do Fundo Nacional de Desenvolvimento da Educação (FNDE) [3], somente

\footnotetext{
2 As ações de aquisição e distribuição de livros didáticos e literários contempladas pelo Programa Nacional do Livro Didático (PNLD) e pelo Programa Nacional Biblioteca da Escola (PNBE) foram unificadas pelo Decreto $n^{\circ}$ 9.099, de 18 de julho de 2017. Assim, a sigla PNLD ganhou nova nomenclatura, significando Programa Nacional do Livro e do Material Didático. Como o último edital para o processo de aquisição de obras didáticas de Física analisado nesse trabalho foi lançado em 2015, seguiremos adotando a nomenclatura anterior.
} 
no PNLD/2019 foram investidos $\mathrm{R} \$ 1.102 .571 .912,18$ na aquisição de mais de 126 milhões de exemplares provenientes de 25 diferentes editoras, englobando: atendimento aos professores da Educação Infantil e a todos os estudantes e professores dos anos iniciais do Ensino Fundamental; reposição dos livros consumíveis para os estudantes e professores dos anos finais do Ensino Fundamental e Ensino Médio; e livros adicionais consumíveis e reutilizáveis para cobrir acréscimos de matrículas para os alunos de todas as séries do Ensino Fundamental e do Ensino Médio.

Apesar de todo o desenvolvimento e acesso às tecnologias digitais que temos hoje em diferentes segmentos da sociedade, o livro didático continua em destaque na Educação Básica. No caso específico do componente curricular da Física, a utilização de livros didáticos em salas de aulas do Ensino Médio público brasileiro, aprovados no Programa Nacional do Livro para o Ensino Médio (PNLEM) e no PNLD, completou dez anos em 2019. Em 2018, foram mais de 7,5 milhões de exemplares de livros de Física distribuídas em todo território nacional pelo PNLD, totalizando em um investimento pelo Governo Federal na ordem de $\mathrm{R} \$ 68$ milhões.

Dado esse vultoso aporte de recursos financeiros, bem como os efeitos da universalização do livro didático na Educação Básica Pública no Brasil, os programas do livro do Governo Federal e os próprios livros didáticos têm despertado atenção e interesse de diversas pesquisas [4-5]. Ao fazer um levantamento de publicações sobre livro didático (LD) em seis periódicos ${ }^{3}$ no período de 2007 a 2014 e em quatro edições de três eventos da área de Ensino de Ciências e Física 4 , Schirmer e Sauerwein [6] identificaram sete principais categorias de análise abordadas por esses estudos (Tabela 1).

Em linhas gerais, podemos separar as pesquisas sobre livro didático de Física e incluir essas categorias em duas grandes vertentes: a primeira seria de caráter mais amplo, voltada para a análise e discussão sobre as implicações das políticas públicas para a produção e inserção do livro didático em sala de aula, bem como o papel das editoras nesse processo; a segunda, de natureza mais es-

3 São eles: Ciência e Educação (C\&E), Ensaio Pesquisa em Educação em Ciências (Ensaio), Investigações em Ensino de Ciências (IENCI), Revista Brasileira de Pesquisa em Educação em Ciências (RBPEC), Revista Brasileira de Ensino de Física (RBEF) e o Caderno Brasileiro de Ensino de Física (CBEF).

${ }^{4}$ São eles: Encontro Nacional de Pesquisa em Educação em Ciências (ENPEC), Simpósio Nacional de Ensino de Física (SNEF) e o Encontro de Pesquisa em Ensino de Física (EPEF). pecífica, porém, mais comum, busca analisar as próprias obras publicadas. Essas duas grandes perspectivas de análise, do conteúdo do livro didático enquanto documento histórico e do livro enquanto produto comercial e determinado por contextos dos mais diversos, também podem ser identificadas em outras áreas [7].

$\mathrm{Na}$ vertente mais específica, as análises das obras didáticas de Física objetivam, em sua maioria, investigar como determinado conceito, tema ou abordagem se faz presente (ou não) na obra analisada. Hidalgo e colaboradores [8], por exemplo, buscaram compreender como os elementos relacionados ao processo de construção histórica do conceito de pressão atmosférica estiveram presentes nos livros didáticos analisados. Já Reis e Martins [9], realizaram um estudo comparativo sobre as atividades experimentais em coleções de Física coincidentes recomendadas nas edições de 2012 e 2015 do PNLD.

Todavia, observamos que, de modo geral, esses critérios de seleção, bem como a própria análise dos dados obtidos (especialmente na vertente específica), não englobam de forma significativa considerações sobre a abrangência nacional de cada coleção, ou seja, o real impacto da adoção dessas coleções nas escolas públicas brasileiras.

Alguns autores optam por selecionar as obras que serão investigadas em função das coleções adotadas em determinada escola, região e/ou por determinado corpo docente. Trintin e Gomes [10], por exemplo, investigaram perfis epistemológicos dos livros didáticos de Física do PNLD de 2018. De um total de 12 (dose) obras, optaram "por aqueles que foram escolhidos pelos professores dos colégios estaduais de Maringá como primeira ou segunda opção" (ibidem, p.46), resultando em 6 (seis) obras selecionadas para análise. Já Darroz, Rosa e Silva [11] investigaram como o tema Física Nuclear tem sido contemplado e estruturado nos livros didáticos de Física do Ensino Médio aprovados no PNLD 2015. De um total de 14 (quatorze) coleções, esses autores optaram por selecionar aquelas adotadas pelas instituições públicas de Ensino Médio da região de Passo Fundo/RS, resultando em 10 (dez) coleções analisadas.

Por outro lado, há aqueles que optam por analisar todas as coleções aprovadas em determinada edição do PNLD. Lima, Ostermann e Cavalcanti ([12], p. 444), por exemplo, analisaram "14 enunciados sobre Física Quântica referente aos 14 livros didáticos aprovados no PNLDEM 2015.". Nessa mesma linha de abrangência, Kopp e Almeida [13] investigaram a presença de analogias

Tabela 1: Categorias e número de publicações sobre livro didático em eventos e periódicos especializados (2007-2014).

\begin{tabular}{lccc}
\hline Categoria & Periódicos & Eventos & Total \\
\hline Aspectos conceituais & 40 & 169 & 209 \\
Inovações, recursos, estratégias e formas de abordagem nos LD & 12 & 61 & 73 \\
Escolha, funções e papel do LD & 4 & 34 & 38 \\
Aspectos linguísticos & 6 & 24 & 30 \\
Aspectos avaliativos de LD & 1 & 11 & 12 \\
Levantamentos em publicações & 1 & 13 & 14 \\
História e políticas do LD & 8 & 10 & 18 \\
Total & 72 & 322 & 394 \\
\hline
\end{tabular}

Fonte: Schirmer e Sauerwein [6]. 
e metáforas em capítulos de Física Moderna de todos os livros didáticos aprovados no PNLD 2018.

Defendemos que, para uma melhor interpretação do impacto dos resultados obtidos, as pesquisas sobre livro didático devem se atentar também para o quantitativo de obras utilizadas ao longo de todo o território nacional e/ou estadual. Uma coleção pode ser amplamente adotada no município ou cidade em que o pesquisador realizou o estudo, mas não refletir a realidade no contexto nacional (e vice-versa), mascarando o real impacto dos resultados obtidos dessas pesquisas e enfraquecendo os critérios de seleção das obras a serem analisadas. Além disso, no caso daquelas pesquisas que optam por selecionar algumas obras de determinado programa do livro, podem estar incorrendo no erro de deixar de fora alguma importante coleção em termos de número de volumes adotados pelas escolas em todo o Brasil, acarretando possíveis interpretações equivocadas ou incompletas dos resultados obtidos.

Portanto, esse artigo objetiva, essencialmente, fornecer subsídios para apoiar e fortalecer pesquisas sobre livro didático de Física do Ensino Médio. Para isso, efetuamos um levantamento do total de coleções adotadas em cada estado brasileiro pelas escolas públicas para o triênio 20182020, destacando e discutindo algumas particularidades.

Os principais questionamentos que guiaram esse estudo foram: Quais coleções de Física se configuram como as mais adotadas em cada estado e região do país e em todo o território brasileiro? Quais as particularidades dessas coleções? Há correlações entre os estados brasileiros com alguma coleção em particular, indicando existir predileção por determinadas obras em certas regiões do país?

\section{Aspectos Metodológicos}

Para o levantamento das coleções de Física nos apoiamos em guias do livro didático publicados pelo Governo Federal nos programas PNLEM e PNLD, os quais possuem resenhas sobre cada coleção e uma discussão geral sobre o processo de análise [14-17].

Com relação ao quantitativo de coleções adotadas pelas escolas públicas brasileiras, concentramos nossos esforços na análise de dados da última edição do PNLD e para escolhas realizadas pelas escolas ao final do ano de 2017 para o triênio 2018-2020. Essas informações foram obtidas através de uma consulta por e-mail feita ao FNDE, as quais também estão disponíveis por meio do Sistema de Material Didático (SIMAD) ${ }^{5}$ Também utilizamos dados estatísticos sobre o PNLD fornecidos pelo FNDE em seu site 6

Não trabalhamos com os dados fornecidos pelo SIMAD, uma vez que se encontravam fragmentados, sendo neces-

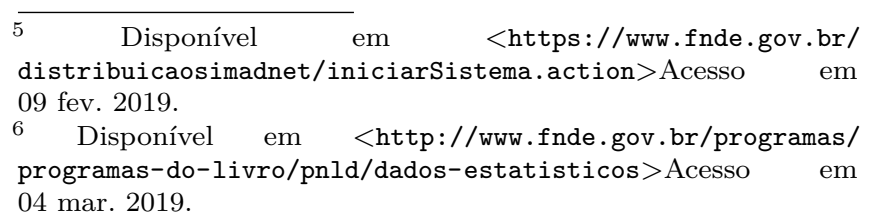

sário informar obrigatoriamente no campo da pesquisa o estado e o município de interesse, dificultando assim a realização de pesquisas mais amplas. Apesar disso, o SIMAD pode ser uma excelente fonte de informações quando se almeja dados mais pontuais, como dados sobre materiais didáticos utilizados pelas escolas de determinado município.

Filtramos os dados brutos de tal modo que, para cada estado mais o Distrito Federal (agrupados por região do Brasil), o número de volumes distintos de uma mesma coleção adotados pelas escolas fosse somado. Desse modo, os dados apresentados nas planilhas e gráficos seguintes não fazem distinção se são obras de Física do primeiro, segundo ou terceiro ano do Ensino Médio, representam apenas o número total de volumes para cada coleção. Seguimos esse procedimento para melhor expor os resultados, além do fato de que cada escola não pode optar por volumes de coleções distintas nos diferentes níveis do Ensino Médio para um mesmo componente curricular.

\section{O Livro Didático de Física no PNLD}

Em cada edição do PNLD é elaborado um Guia de Livros Didáticos contendo resenhas de todas as obras aprovadas. Tem por principal objetivo orientar os professores e equipe pedagógica na escolha do livro didático que será adotado pela escola durante um período de três anos. A última edição do Guia de Livros Didáticos de Física trouxe resenhas de 12 (doze) coleções aprovadas [17], segunda maior quantidade de obras aprovadas dentre as quatro edições do Programa Nacional do Livro Didático de Física. A edição de 2015 do PNLD apresentou 14 (quatorze) coleções aprovadas [16]. Nas edições de 2012 e 2009 foram aprovadas 10 (dez) e 6 (seis) coleções, respectivamente [15-16].

De todas as obras de Física submetidas na primeira edição do Programa Nacional do Livro Didático para o Ensino Médio, apenas 27\% foram aprovadas. Esse percentual aumentou consideravelmente na última edição, de todas as coleções submetidas, $75 \%$ foram aprovadas [17].

Todo o processo de funcionamento do PNLD, desde a inscrição das editoras até a distribuição dos livros, é descrito e discutido por Di Giorgi e colaboradores [18] e Britto [5]. Esse processo não sofreu significativas mudanças entre as últimas edições do programa. Uma das etapas é a de triagem e avaliação de qualidade técnica e pedagógica dos livros recebidos pelo MEC. A atualização dos conteúdos e procedimentos mobilizados pela obra constitui em um dos principais critérios para a análise do livro nessa etapa de avaliação.

No caso específico da Física (ou de qualquer outra ciência), não podemos esquecer que se trata de uma construção humana e, como tal, está em contínuas transformações. Somado a isso, o desenvolvimento científico e tecnológico podem desencadear rápidas e significativas mudanças nas relações humanas, nas dinâmicas sociais, na economia e no meio ambiente, dentre outros fatores. 
"É hoje indefensável, na educação básica, o desenvolvimento de um ensino de Física organizado exclusivamente a partir de seu formalismo." ([17], p. 10).

As coleções de Física indicadas pelo MEC para serem utilizadas nas escolas públicas ao longo dos últimos dez anos estão especificadas no Apêndice A. Trata-se de coleções aprovadas no PNLEM (edição de 2009) e no PNLD (edições de 2012, 2015 e 2018).

As obras de Física em volume único estiveram presentes apenas no PNLEM, edição de 2009. Isso, foi uma consequência direta do PNLD (edições de 2012, 2015 e 2018) em que, por determinação do próprio edital, as obras foram obrigatoriamente organizadas por ano e em coleção, não aceitando obras em volume único para o componente curricular de Física [19-22].

Os autores cujas coleções de Física foram aprovadas e recomendadas em todos os quatro editais de seleção do livro didático estão indicados na Tabela 2 .

De certo modo, essas observações apontam para o que Souza (1999, apud [23], p.89) coloca como "ilusão de autoria", ou seja, "ao autor não é conferida autonomia sobre seu material, visto que este está em consonância com as necessidades e padrões estipulados pela editora". Por sua vez, para o processo de inscrição e avaliação de obras didáticas a serem adotadas no setor público, as próprias editoras e, consequentemente, as obras inscritas, também estão submetidas aos critérios determinados pelos editais de convocação do Ministério da Educação (um dos principais exemplos reside na limitação do número de páginas por volume).

\section{Classificação dos Livros Didáticos de Física do PNLD para o Triênio 2018-2020}

No ranking geral de livros mais adotados para o triênio 2018-2020, identificamos que cinco coleções se destacaram no território nacional. As duas primeiras colocadas são de uma mesma editora, FTD. A coleção de Bonjorno, Casemiro, Clinton e Eduardo Prado foi a mais adotada em 2018 em todas as regiões do país, especialmente nas regiões sudeste e nordeste, totalizando em mais de um milhão e meio de volumes. A segunda foi a coleção de Benigno Barreto e Claudio Xavier, especialmente nas regiões nordeste, sudeste e sul. A coleção de Adriana Benetti et al pela editora SM foi a segunda mais adotada somente na região norte.

Importante destacar que, apesar de já existirem obras didáticas de Física para a Educação Básica com autoria de Bonjorno, décadas antes do primeiro programa do livro que contemplou esse componente curricular, a coleção de Bonjorno e colaboradores passou a ingressar o Guia do Livro Didático do PNLD apenas na edição de 2015. Por sua vez, a coleção de Barreto e Xavier tem sido aprovada e indicada desde o PNLD/2009 e a coleção de Adriana Benetti et al se fez presente apenas na última edição do PNLD7. Ainda assim, as três coleções que se destacaram em 2018 estão também entre as três coleções com maior número de volumes distribuídos no PNLD/2015 (ver Apêndice B). A coleção de Bonjorno e colaboradores se manteve na primeira posição no PNLD/2015 e no PNLD/2018. A segunda posição foi alternada, em 2015 ficou com a coleção Ser Protagonista (editora SM), em vez da coleção Física Aula por Aula (editora FTD), que ficou na terceira posição. $\mathrm{O}$ valor pago pelo MEC por cada volume, assim como o código de cada coleção aprovada no PNLD/2018 está especificado na Tabela 3.

Os gráficos seguintes (Figuras 1-5) expõem o número total de livros de cada coleção de Física (considerando todos os volumes somados) escolhida pelas escolas públicas ao final de 2017 para o triênio 2018-2020 em cada estado brasileiro (agrupados por região). As cores de cada se-

\footnotetext{
7 O PNLD/2015 aprovou uma obra intitulada Ser Protagonista Física, mesmo título da coleção de Adriana Benetti e colaboradores no PNLD/2018, mas se trata de uma obra de autoria de Angelo Stefanovits, que não fez parte da equipe de autores na última edição aprovada.
}

Tabela 2: Autores indicados em todos os Programas do Livro Didático de Física.

\begin{tabular}{|c|c|c|c|c|c|}
\hline \multicolumn{6}{|c|}{ Relação de autores com coleções aprovadas em todos os programas do Livro Didático de Física para o Ensino Médio } \\
\hline Autores & Programa & Título & Editora & Edição/Ano & Páginas \\
\hline \multirow{4}{*}{$\begin{array}{l}\text { Carlos Magno A. } \\
\text { Torres }\end{array}$} & PNLEM/2009 & \multirow{4}{*}{$\begin{array}{l}\text { Física - Ciência e } \\
\text { Tecnologia }\end{array}$} & \multirow[t]{4}{*}{ Moderna } & $1^{\mathrm{a}} \mathrm{Ed} . / 2005$ & 706 \\
\hline & PNLD/2012 & & & $2^{\mathrm{a}}$ Ed. $/ 2010$ & 944 \\
\hline & PNLD/2015 & & & $3^{\mathrm{a}}$ Ed. $/ 2013$ & 912 \\
\hline & PNLD/2018 & & & $4^{\mathrm{a}}$ Ed. $/ 2016$ & 856 \\
\hline \multirow{4}{*}{$\begin{array}{l}\text { Antônio Máximo } \\
\text { Ribeiro da Luz; } \\
\text { Beatriz Alvarenga } \\
\text { Álvares }\end{array}$} & PNLEM/2009 & Física & \multirow[t]{4}{*}{ Scipione } & $1^{\mathrm{a}}$ Ed./2005 & 1192 \\
\hline & PNLD/2012 & Curso de Física & & $1^{\mathrm{a}}$ Ed. $/ 2010$ & 1208 \\
\hline & PNLD/2015 & Física: Contexto \& & & $1^{\mathrm{a}}$ Ed./2013 & 960 \\
\hline & PNLD/2018 & Aplicações & & $2^{\mathrm{a}}$ Ed./2016 & 824 \\
\hline \multirow[t]{4}{*}{ Alberto Gaspar } & PNLEM/2009 & Física & \multirow[t]{4}{*}{ Ática } & $1^{\mathrm{a}} \mathrm{Ed} . / 2005$ & 472 \\
\hline & PNLD/2012 & \multirow{3}{*}{ Compreendendo a Física } & & $1^{\mathrm{a}}$ Ed. $/ 2010$ & 1240 \\
\hline & PNLD/2015 & & & $2^{\mathrm{a}}$ Ed. $/ 2013$ & 944 \\
\hline & PNLD/2018 & & & $3^{\mathrm{a}} \mathrm{Ed} . / 2016$ & 864 \\
\hline \multirow{4}{*}{$\begin{array}{l}\text { Aurélio Gonçalves } \\
\text { Filho; Carlos Toscano }\end{array}$} & PNLEM/2009 & Física & \multirow[t]{2}{*}{ Scipione } & $1^{\mathrm{a}}$ Ed./2005 & 472 \\
\hline & PNLD/2012 & Física e Realidade & & $1^{\mathrm{a}}$ Ed./2010 & 679 \\
\hline & PNLD/2015 & Física: Interações e & \multirow[t]{2}{*}{ Leya } & $1^{\mathrm{a}}$ Ed. $/ 2013$ & 736 \\
\hline & PNLD/2018 & Tecnologia & & $2^{\mathrm{a}}$ Ed. $/ 2016$ & 766 \\
\hline
\end{tabular}


Tabela 3: Valores de cada volume (livro do aluno) - PNLD/2018.

\begin{tabular}{|c|c|c|c|c|c|}
\hline \multicolumn{6}{|c|}{ Valores de cada volume (livro do aluno) para aquisições efetuadas pelo MEC com distribuição em 2018} \\
\hline \multirow{2}{*}{ Código } & \multirow[t]{2}{*}{ Título/ Autores } & \multirow[t]{2}{*}{ Editora } & \multicolumn{3}{|c|}{ Valor $(\mathrm{R} \$)$} \\
\hline & & & Vol. 1 & Vol. 2 & Vol. 3 \\
\hline 0021P18133 & Física/ Carron; Guimarães; Piqueira & Ática & 8,45 & 8,23 & 8,45 \\
\hline $0025 \mathrm{P} 18133$ & Compreendendo a Física/ Alberto Gaspar & Ática & 8,45 & 8,45 & 8,45 \\
\hline $0045 \mathrm{P} 1813$ & $\begin{array}{l}\text { Física: Contexto \& Aplicações/ Antônio Máximo; Beatriz } \\
\text { Alvarenga; Carla Guimarães }\end{array}$ & Scipione & 8,62 & 7,71 & 8,39 \\
\hline 0071P18133 & $\begin{array}{l}\text { Ser Protagonista - Física/ Adriana Benetti Marques Vá- } \\
\text { lio; Ana Fukui; Ana Paula Souza Nani; Bassam Ferdinian; } \\
\text { Madson de Melo Molina; Gladstone Alvarenga de Oliveira; } \\
\text { Venê }\end{array}$ & SM & 8,79 & 8,79 & 8,79 \\
\hline 0100P18133 & $\begin{array}{l}\text { Física para o Ensino Médio/ Kazuhito Yamamoto; Luiz } \\
\text { Felipe Fuke }\end{array}$ & Saraiva & 8,50 & 8,50 & 8,50 \\
\hline 0101P18133 & $\begin{array}{l}\text { Física/ Ricardo Helou Doca; Gualter José Biscuola; Newton } \\
\text { Villas Bôas }\end{array}$ & Saraiva & 8,50 & 10,24 & 10,24 \\
\hline 0118P18133 & $\begin{array}{l}\text { Física: Interação e Tecnologia/ Aurelio Gonçalves Filho; } \\
\text { Carlos Toscano }\end{array}$ & Leya & 12,16 & 10,24 & 10,24 \\
\hline 0129P18133 & Física aula por aula/ Benigno Barreto; Claudio Xavier & FTD & 8,90 & 8,90 & 7,96 \\
\hline 0131P18133 & Física/ Bonjorno; Casemiro; Clinton; Eduardo Prado & FTD & 8,90 & 8,90 & 8,43 \\
\hline 0167P18133 & $\begin{array}{l}\text { Física em Contextos/ Alexander Pogibin; Maurício Pietro- } \\
\text { cola; Renata de Andrade; Talita Raquel Romero }\end{array}$ & Editora do Brasil & 14,31 & 14,31 & 14,31 \\
\hline 0188P18133 & $\begin{array}{l}\text { Física - Ciência e Tecnologia/ Carlos Magno A. Torres; Nico- } \\
\text { lau Gilberto Ferraro; Paulo Antônio de Toledo Soares; Paulo } \\
\text { Cesar Martins Penteado }\end{array}$ & Moderna & 8,62 & 8,39 & 8,62 \\
\hline 0200P18133 & $\begin{array}{l}\text { Conexões com a Física/ Blaidi Sant'anna; Glorinha Martini; } \\
\text { Hugo Carneiro Reis; Walter Spinelli }\end{array}$ & Moderna & 8,62 & 8,62 & 8,39 \\
\hline
\end{tabular}
Fonte: Autoria própria.

Distribuição livros para o Nordeste

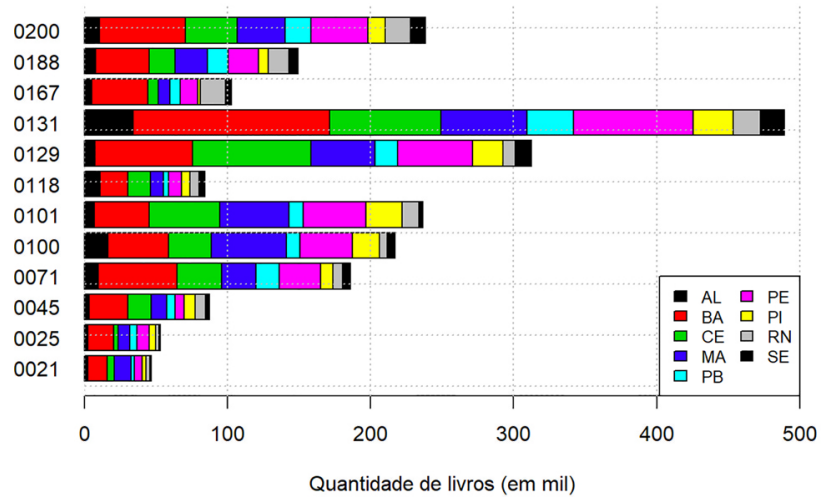

Figura 1: Quantidade de livros do aluno por coleção de Física no PNLD/2018 - Região Nordeste. Fonte: Autoria própria.

guimento das barras representam os estados. Os códigos que indicam a coleção estão em sua forma resumida nos gráficos. Na sequência, o gráfico indicado pela Figura 6 reúne esses dados e traz o total geral de livros de cada coleção adotados no Brasil.

Analisamos os dados também em busca de responder à seguinte questão: há correlações entre os estados com alguma coleção em particular, indicando existir predileção por determinadas obras em certas regiões devido a possíveis particularidades socioculturais?

Constatamos que a resposta foi negativa, pois, observouse uma significativa uniformidade ao longo de todo o território brasileiro referente à coleção com maior número
Distribuição livros para a Região Sudeste

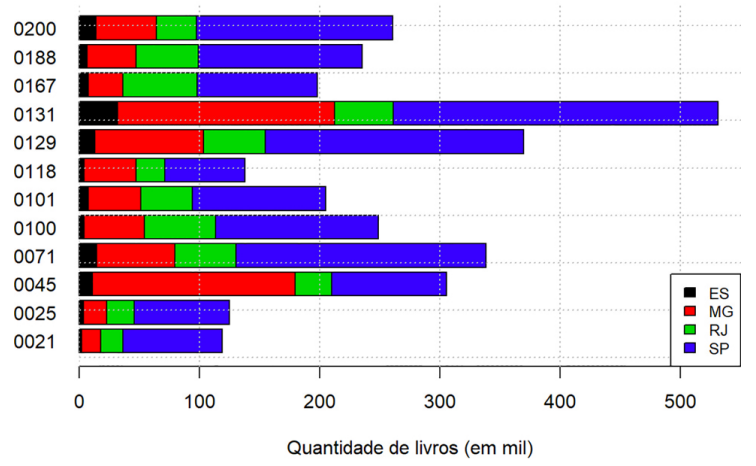

Figura 2: Quantidade de livros do aluno por coleção de Física no PNLD/2018 - Região Sudeste. Fonte: Autoria própria.

Distribuição livros para a Região Norte

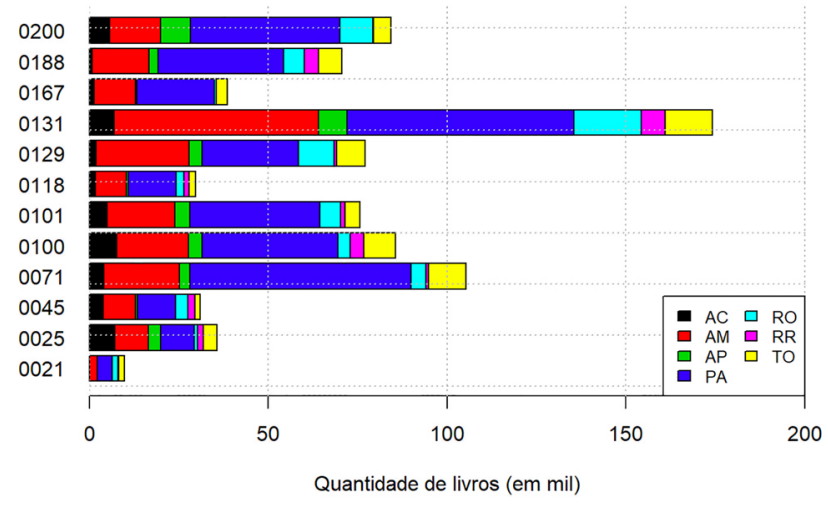

Figura 3: Quantidade de livros do aluno por coleção de Física no PNLD/2018 - Região Norte. Fonte: Autoria própria. 
Distribuição livros para a Região Sul

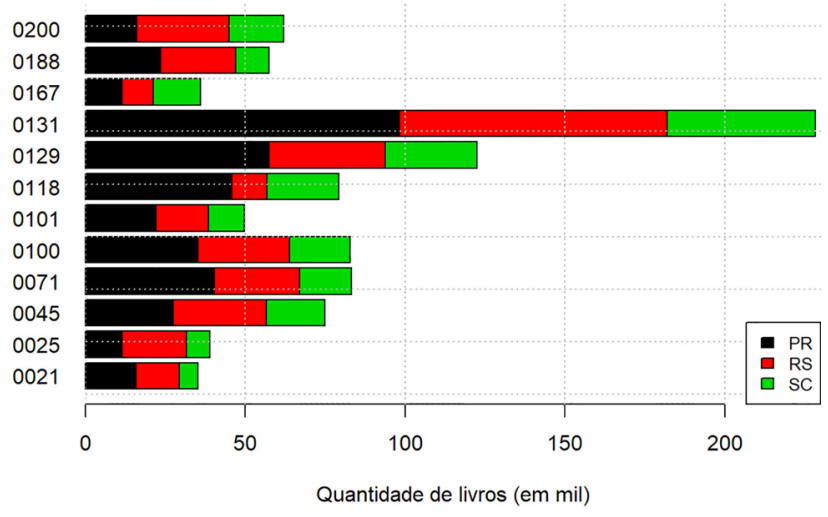

Figura 4: Quantidade de livros do aluno por coleção de Física no PNLD/2018 - Região Sul. Fonte: Autoria própria.

de livros adotados pelas escolas para o triênio 2018-2020 (Figura 7).

A coleção 0131 (Bonjorno, Casemiro, Clinton e Eduardo Prado) esteve com maior número de livros adotados em 21 (vinte e um) estados. Na sequência, temos a coleção 0129, de Benigno Barreto e Claudio Xavier, predominante nos estados Ceará e Mato Grosso do Sul e no Distrito Federal. As coleções 0100 (Fuke e Kazuhito), 0167 (Maurício Pietrocola, Alexander Pogibin, Renata de Andrade e Talita Raquel Romero) e 0200 (Blaidi Sant'anna, Glorinha Martini, Hugo Carneiro Reis e Walter Spinelli) foram destaques apenas em um estado cada, Acre, Rio de Janeiro e Amapá, respectivamente.

É preciso nos questionarmos e nos aprofundarmos em estudos que possam auxiliar em uma melhor intepretação e impacto desse cenário, especialmente quando consideramos que o livro didático pode interferir em diversas dimensões da experiência escolar, por exemplo: na seleção de tópicos a serem abordados; nos enfoques
Distribuição livros para a Região Centro-Oeste

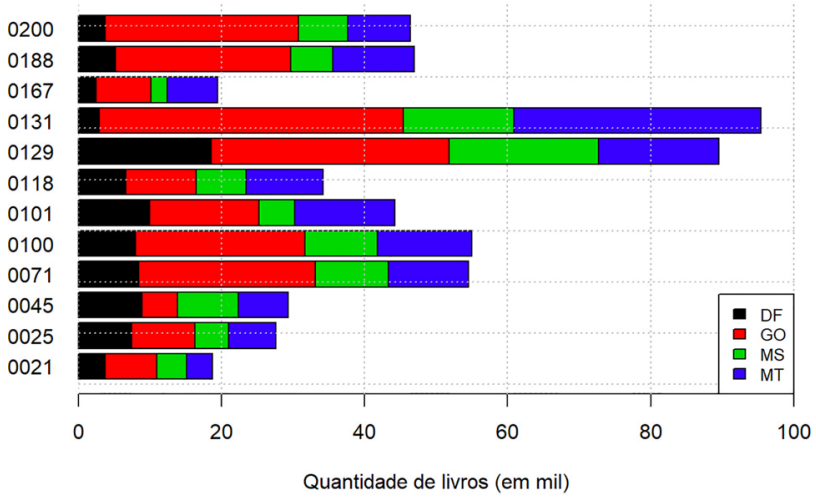

Figura 5: Quantidade de livros do aluno por coleção de Física no PNLD/2018 - Região Centro-Oeste. Fonte: Autoria própria.

historiográficos e filosóficos; nas propostas de práticas experimentais e extracurriculares; nos processos avaliativos; nas concepções e visões de mundo; nas estratégias didático-pedagógicas e práticas docentes, dentre outras [4, 24-26]. Além disso, os programas de aquisição de livros didáticos executados pelo Governo Federal "têm sido alvo de críticas relacionadas a supostos vieses políticos e equívocos pedagógicos." ([5], p. 4).

\subsection{Observações, questionamentos e interpretações}

As escolas públicas têm autonomia para escolher duas opções de coleções de editoras diferentes, indicando a ordem de prioridade ou se não deseja receber livros diferentes da primeira opção. O FNDE recomenda que a escolha dessas coleções ocorra a partir de uma reflexão coletiva entre os professores e com base no guia do livro didático, além de consulta direta aos exemplares do professor disponibilizados pelas editoras.

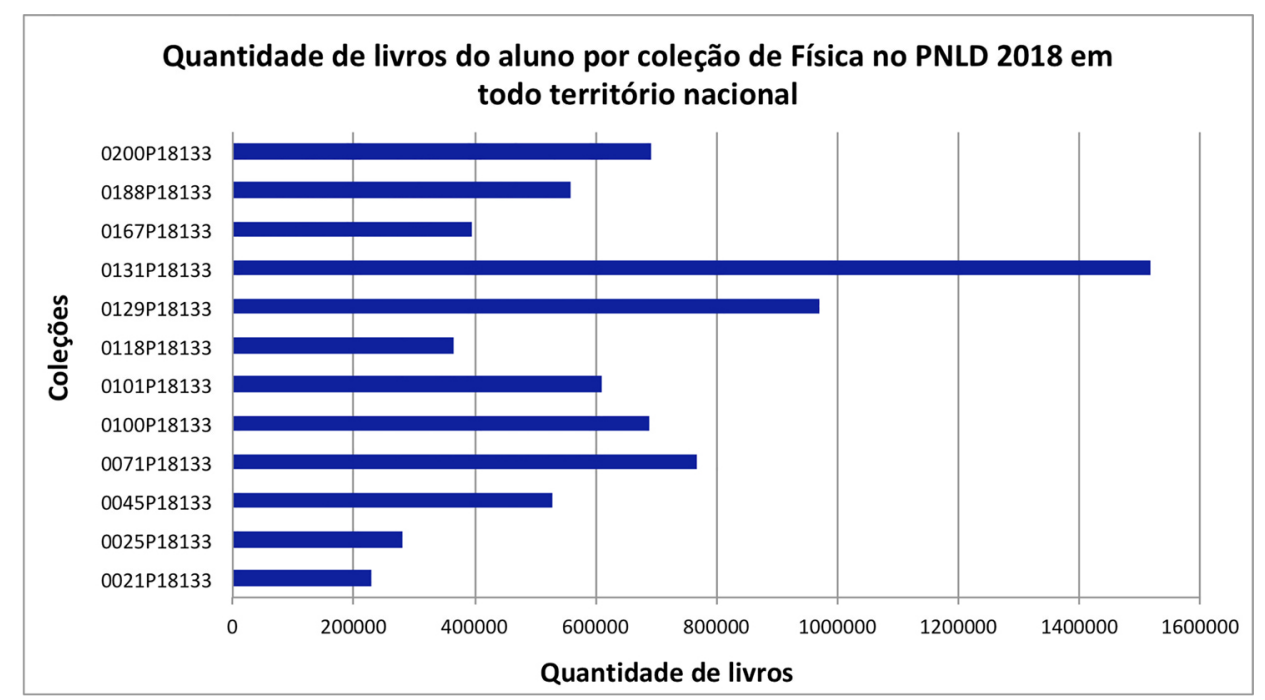

Figura 6: Quantidade de livros do aluno por coleção de Física no PNLD/2018 - Brasil. Fonte: Autoria própria. 


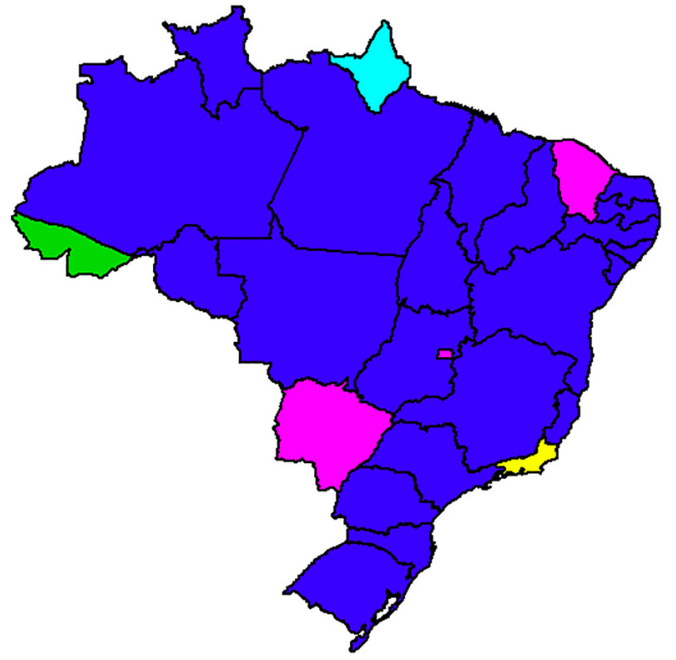

Mapa dos estados segundo o Livro mais Adotado no PNLD 2018
$\square$ 0100P1813310 $\square$ 0131P1813310 $\square$ 0200P1813310
$\square$ 0129P1813310 $\square$ 0167P1813310

Figura 7: Mapa dos estados brasileiros, segundo a coleção de Física (livro do aluno) mais adotada no PNLD/2018 - Ensino Médio. Fonte: Autoria própria.

Entretanto, os critérios de escolha dos livros didáticos pelos professores nas escolas são os mais diversos e, comumente, os menos adequados [27-29]. Os fatores que determinam a escolha de um livro didático por parte do corpo docente da escola podem variar desde questões de ordem didático-pedagógica, que seria um fator ideal e desejável, até questões que fogem da razoabilidade, como, por exemplo, o pesd 8 . Também não podemos negar a influência do mercado editorial nesse processo, o que abre um leque de possibilidades para a interpretação do porquê determinadas obras se destacaram. "As editoras, ao conquistarem o direto de fabricar e divulgar o livro didático, trataram de transformá-lo em uma mercadoria inserida na lógica capitalista." ([1], p. 77. Grifo nosso.). Nesse aspecto, Zambon e Terrazzan ([27], p. 598) observaram que:

\section{[...] a execução do PNLD e a organização do processo de escolha de livros didáticos nas es- colas têm sido desencadeadas muito mais por ações desenvolvidas pelas editoras do que pro- priamente por orientações do MEC/FNDE ou das instâncias político-administrativas da}

\footnotetext{
8 No ano de 2008, um dos autores desse artigo, na época professor concursado da Educação Básica do estado de São Paulo, estava em sala de aula e acompanhou de perto o processo de escolha das coleções de Física por aquela escola que lecionava. Foi então convidado para se reunir junto aos demais professores de Física para determinar qual coleção seria adotada pela escola em razão do PNLEM de 2009. Seguiu-se que a escolha de nosso autor, que levou em conta a qualidade da obra em termos de conteúdo e abordagem, foi voto vencido. Escolheu-se o livro de Física mais fino, ou seja, aquele mais leve, no argumento que os alunos precisavam transportar muitos volumes de livros e não se tinha onde armazenar na escola.
}

Secretaria Estadual de Educação. [...] no processo de escolha de livros didáticos, é bastante comum a realização de encontros breves na sala de professores e/ou durante o intervalo das aulas, em que os docentes costumam tomar suas decisões de caráter coletivo acerca dos livros a serem escolhidos.

É preciso destacar ainda o papel do próprio Ministério da Educação que, por intermédio do FNDE, pode determinar qual a coleção que será encaminhada para a escola quando a instituição não efetuou a escolha, mas está inclusa no programa do livro. O texto encaminhado para as escolas pelo FNDE com um passo a passo sobre o processo de escolha do livro no PNLD/2018 avisa que se a escola "não acessar o Sistema ou não gravar sua escolha serão encaminhados, compulsoriamente, um dos títulos dentre aqueles aprovados e que se encontram no guia, para cada componente curricular. $9^{9}$

Não conseguimos obter informações oficiais junto ao FNDE sobre quais os critérios adotados para definir qual a coleção será encaminhada para as escolas nesses casos. Britto [5], em trabalho publicado pelo Centro de Estudos da Consultoria do Senado Federal, destaca que a aquisição do livro didático pelo FNDE é realizada por inexigibilidade de licitação, uma vez que que as escolhas dos livros são efetivadas pelos professores. Quando a escola não sinaliza a escolha do livro que será adotado para aquele triênio, receberá exemplares correspondentes aos livros mais solicitados na sua região. Britto ([5], p. 8) detalha ainda que,
Concluída a negociação, o FNDE firma um contrato com cada editora, com quantitativos baseados em projeções do número de alunos nas escolas, calculadas a partir do Censo Es- colar mais atualizado. Não havendo acordo entre as partes em relação ao preço, o regula- mento permite que o FNDE, em respeito ao princípio da economicidade, contrate a aquisi- ção de obras escolhidas em segunda opção. Na eventualidade de novo impasse, o Fundo pode negociar a aquisição da obra mais escolhida na região da escola.

Da nossa experiência com diversos docentes da Educação Básica Pública, não é incomum ouvir relatos afirmando que foram entregues livros didáticos que não constavam nas opções indicadas pelo corpo docente, seja como primeira ou segunda opção. Di Giorgi e colaboradores ([18], p.1035) reforça essa observação ao destacar que há um "desgaste/desencanto causado pelo fato recorrente de suas escolhas não serem contempladas". Isso poderia resultar em uma das principais razões de existirem diversas escolas que não enviam suas indicações de livro que será adotado (ibidem).

\footnotetext{
9 Texto disponível em: <https://www.fnde.gov.br/programas/ programas-do-livro/pnld/guia-do-livro-didatico/item/ 11148-guia-pnld-2018>Acesso em 23 fev. 2019.
} 
A análise pontual das obras de Física que identificamos em destaque em cada estado brasileiro e adotadas para o triênio 2018-2020, foge inteiramente do escopo desse trabalho, especialmente por limitações de espaço para a publicação. Contudo, não podemos deixar de mencionar duas importantes observações sobre a coleção que se encontra no topo do ranking das obras mais adotadas pelas escolas nas duas últimas edições do PNLD. De acordo com o próprio Guia do livro didático, na coleção de Bonjorno e colaboradores, edição aprovada no PNLD 2018, "dentre todo o rol de atividades propostas, a principal ênfase está atribuída aos exercícios quantitativos [...]". ([17], p. 76). Além disso,

Questões socioambientais e de sustentabilidade não ocupam lugar de destaque na coleção, já que são escassas as propostas voltadas a discussões sociocientíficas. Essa característica limita a exploração das relações entre Ciência, Tecnologia, Sociedade e Meio Ambiente, principalmente quanto ao desenvolvimento do posicionamento crítico dos estudantes e suas ações socioambientais. (ibidem, p.79. Grifo nosso).

De acordo com os dados para as duas últimas edições do PNLD, o enfoque mais tradicional, enfatizando os aspectos quantitativos da Física na Educação Básica, seria, de fato, o perfil de obra didática que a maioria dos docentes tem buscado? Ou estaria o Governo Federal ignorando as escolhas efetuadas pelos professores e priorizando aspectos puramente econômicos? O valor pago pelo MEC para aquisição de cada volume poderia ser empregado para melhor compreender a adoção desse elevado número de volumes da coleção de Bonjorno e colaboradores publicada pela editora FTD em todo o território nacional?

Ao que tange os aspectos econômicos, observamos que no PNLD/2018 foram 8 (oito) editoras aprovadas para o componente curricular de Física. Os valores pagos para cada exemplar do aluno variavam de $R \$ 7,71$ até $R \$$ 14,31 (Tabela 3). Os livros publicados pela editora FTD estão justamente entre os de menor valor. A coleção publicada pela Editora do Brasil é a que apresenta custo mais elevado, considerando as aquisições efetuadas pelo Ministério da Educação do Brasil para distribuição no ano de 2018.

Destacamos ainda que autores como Alberto Gaspar, Beatriz Alvarenga e Antônio Máximo são considerados por vários pesquisadores brasileiros como uns dos mais influentes na história do livro didático de Física em nosso país. Esses autores foram protagonistas de importantes mudanças na forma e no conteúdo das coleções de Física. Mello e Garcia ([30], p. 561) destacam que

Um livro de Física brasileiro considerado longevo é o elaborado pelos professores Beatriz Alvarenga e Antônio Máximo, adotados no
Brasil desde a década de 1970. Desde sua primeira edição até hoje, tem tido boa aceitação por professores e alunos, tendo sido aprovado nas últimas seleções de livros do Programa Nacional do Livro Didático [...]

Contudo, nos parece que esse background não influenciou significativamente o processo de escolha das obras ao observarmos os dados para todo o território nacional. Os resultados apontam que a coleção Compreendendo a Física, de Alberto Gaspar e publicado pela editora Ática (código 0025), por exemplo, é a penúltima colocada no ranking geral em número de livros adotados pelas escolas públicas no Brasil em 2018. Por sua vez, a coleção de Beatriz Alvarenga, Antônio Máximo e Carla Guimarães (presente entre os autores desta obra a partir da última edição), publicado pela editora Scipione (código 0045), localiza-se na $8^{a}$ posição em um ranking com 12 (doze) obras. Quando observados os dados referentes ao PNLD/2015 (Apêndice B), a obra de Antônio Máximo e Beatriz Alvarenga encontra-se em uma situação bem melhor, ocupando a quarta posição em um ranking com 14 (quatorze) coleções. Todavia, a coleção de Alberto Gaspar continua em penúltimo lugar dentre os 14 (quatorze) títulos com maior número de volumes distribuídos no PNLD/2015.

Enfim, sinalizamos que todas essas informações podem representar um resultado importante para ser levado em consideração pelas pesquisas da linha de análise de livro didático, subsidiando critérios de escolhas sobre qual obra será analisada e fortalecendo uma melhor interpretação dos resultados obtidos. Ademais, destacamos que os dados compilados, apresentados e discutidos nesse artigo, apontam para dois principais possíveis cenários, ambos lamentáveis para a qualidade do ensino de Física no Brasil. O primeiro cenário seriam possíveis irregularidades, ingerências administrativas e/ou condutas que não respeitam a vontade do corpo docente ao distribuírem o livro didático de Física para as escolas. O segundo seria que o próprio corpo docente tem, de fato, optado por obras com perfil mais tradicional, organizadas fortemente a partir do formalismo da Física.

Disponibilizamos no Apêndice $\mathrm{C}$ deste artigo os valores absolutos do número de livros para cada coleção adotados pelos estados brasileiros mais o Distrito Federal para o triênio 2018-2020.

\section{Considerações Finais}

Ainda há várias outras questões que permanecem em aberto, tais como: seria a abordagem mais tradicional e os fatores econômicos, de fato, os aspectos determinantes para uma coleção de Física se destacar em todo o território nacional em termos de número de livros adotados pelas escolas públicas brasileiras, como o observado para o triênio 2018-2020? Qual o perfil detalhado das obras de Física mais adotadas e o que as diferenciam? Haveria correlações entre elas que poderiam, minimamente, expli- 
car a posição que ocupam no ranking das mais adotadas? Até que ponto vai a influência (ilegal) das editoras nos processos de escolha do livro didático pelo corpo docente que poderia justificar esses destaques?

Também podemos nos indagar sobre os livros didáticos para os demais componentes curriculares da área de ciências no Ensino Médio, por exemplo: as coleções de Química, Biologia e Física de um mesmo PNLD, identificadas como as mais adotadas no Brasil na rede pública seriam aquelas publicadas pelas mesmas editoras? Se sim, quais seriam as particularidades dessas obras que justificaria tamanha convergência? Qual seria o ranking em número de coleções adotadas nas edições anteriores do PNLD para as componentes curriculares de Física, Química e Biologia? Haveria algum padrão?

Apesar da profundidade e relevância dessas questões, foge inteiramente do escopo desse trabalho tentar esclarecêlas ou solucioná-las nesse primeiro momento. Todavia, foi possível formar uma base de dados que pode dar suporte a outras pesquisas na linha de análise de livro didático, especialmente aqueles do componente curricular de Física aprovados pelo PNLEM e PNLD. Também já iniciamos o processamento e análise de dados obtidos junto ao FNDE para as coleções de Química e Biologia adotadas em 2018, promovendo a construção de um panorama sobre os livros didáticos da área de ciências da natureza no Ensino Médio em todo o território nacional. Esperamos que em breve possamos publicar os resultados dessas análises, acompanhadas de discussões que possam esclarecer algumas das questões em aberto levantadas acima.

\section{Agradecimentos}

Agradecemos ao Fundo Nacional de Desenvolvimento da Educação (FNDE), especialmente à Equipe do Livro Didático, às professoras Juliana Schivani, Eliziane Ataliba, Rafaela Lemos, Izabel Nascimento e Rosanne Bezerra, e aos professores Henrique Coelho e Glauco dos Santos pelas valiosas contribuições que auxiliaram no desenvolvimento dessa pesquisa e na escrita desse artigo.

\section{Material suplementar}

Os seguintes materiais estão disponíveis online:

Apêndice A - Coleções de Física aprovadas pelos programas do livro do Governo Federal.

Apênđice $\overline{\mathbf{B}}$ - Classificação das coleções em função do número de exemplares distribuídas no PNLD/2015 e PNLD/2018.

Apêndice C - Número total de volumes de cada coleção de Física (livro do aluno) adotadas por estado e pelo DF em 2017 para o triênio 2018-2020 (PNLD 2018).

\section{Referências}

[1] C.M.F. Bittencourt, Educ. Pesqui. 30, 471 (2004).
[2] C.C.F. Cassiano, O mercado do livro didático no Brasil: da criação do Programa Nacional do Livro Didático (PNLD) à entrada do capital internacional espanhol (1985-2007). Tese de Doutorado, Pontifícia Universidade Católica de São Paulo, São Paulo (2007).

[3] BRASIL, Dados estatísticos - PNLD 2019 (Ministério da Educação, Brasília, 2019).

[4] N.M.D. Garcia, O livro didático de Física e de Ciências em foco: dez anos de pesquisa (Editora Livraria da Física, São Paulo, 2017), $1^{\mathrm{a}}$ ed.

[5] T.F. Britto, O Livro Didático, o Mercado Editorial e os Sistemas de Ensino Apostilados (Centro de Estudos da Consultoria do Senado, Brasília, 2011)

[6] S.B. Schirmer e I.P.S. Sauerwein, Inv. Ens. de Ciênc. 22, 23 (2017).

[7] A. Choppin. Educ. Pesqui. 30, 549 (2004).

[8] J.M. Hidalgo, J.M. Alves, F.A. Souza, D.M. Queiroz e R. Alexandria, Educ. Ci. Tec 11, 101 (2018).

[9] W.F. Reis e M.I. Martins, Cad. Bras. Ens. Fís. 33, 462 (2016).

[10] R.S. Trintin e L.C. Gomes, Acta Scientiae 20, 2 (2018).

[11] L.M. Darroz, C.T.W da Rosa e J.C. da Silva, Revista de Educação, Ciências e Matemática 7, 3 (2017).

[12] N.W. Lima, F. Ostermann e C.J.H. Cavalcanti, Cad. Bras. Ens. Fís. 34, 435 (2017).

[13] F.A. Kopp e V. de Almeida, Cad. Bras. de Ens. de Fís. 36, 69 (2019).

[14] BRASIL, Física: catálogo do Programa Nacional do Livro para o Ensino Médio: PNLEM 2009 (Ministério da Educação, Brasília, 2008).

[15] BRASIL, Guia de livros didáticos: PNLD 2012 - Física (Ensino Médio) (Ministério da Educação, Brasília, 2011).

[16] BRASIL, Guia de livros didáticos: PNLD 2015 - Física (Ensino Médio) (Ministério da Educação, Brasília, 2014).

[17] BRASIL, Guia de livros didáticos: PNLD 2018 - Fúsica (Ensino Médio) (Ministério da Educação, Brasília, 2017).

[18] C.A.G. Di Giorgi, S.C.N. Militão, A.N. Militão, F. Perboni, R.C. Ramos, V.M.M. Lima e Y.U.F. Leite, Ensaio: Aval. Pol. Públ. Educ. 22, 1027 (2014).

[19] BRASIL, Edital de convocação para inscrição no processo de avaliação e seleção de obras didáticas a serem incluídas no catálogo do programa nacional do livro para o Ensino Médio- PNLEM/2007 (Ministério da Educação, Brasília, 2005).

[20] BRASIL, Edital de convocação para inscrição no processo de avaliação e seleção de obras didáticas para o programa nacional do livro didático PNLD 2012 - Ensino Médio (Ministério da Educação, Brasília, 2009).

[21] BRASIL, Edital de convocação para inscrição no processo de avaliação e seleção de obras didáticas para o programa nacional do livro didático PNLD 2015 - Ensino Médio (Ministério da Educação, Brasília, 2013).

[22] BRASIL, Edital de convocação para inscrição no processo de avaliação e seleção de obras didáticas para o programa nacional do livro didático PNLD 2018 - Ensino Médio (Ministério da Educação, Brasília, 2015).

[23] E. Andrade, Quaestio - Revista de Estudos em Educação 5, 75 (2003).

[24] M.H.S. Carneiro, W.L.P. dos Santos e G.S. Mól. Ens. Pesqui. Educ. Ciênc. 7, 101 (2005).

[25] C.R. Pagliarini, Uma análise da história e filosofia da ciência presente em livros didáticos de física para o 
ensino médio. Dissertação de Mestrado, Instituto de Física de São Carlos, Universidade de São Paulo, São Paulo (2007).

[26] J.U.P. Moraes, Scientia Plena 7, 094401-1 (2011).

[27] L.B. Zambon e E.A. Terrazzan, Rev. Bras. Estud. Pedagog. 94, 585 (2013).

[28] A.A. Martins, Artefato da cultura escolar ou mercadoria? A escolha do livro didaitico de Fiisica em anailise. Tese de Doutorado, Universidade Federal do Paranaì, Curitiba (2014).

[29] M. D'Aquino Rosa e A. Mohr, Ens. Pesqui. Educ. Ciênc. 18, 97 (2016).

[30] A.C. Mello e N.M.D. Garcia, in O livro didático de Física e de Ciências em foco: dez anos de pesquisa, organizado por N.M.D. Garcia (Editora Livraria da Física, São Paulo, 2017). 